\title{
Non-Compact Cardiomyopathy: A Rare Pathology in Sri Lankan Context
}

\author{
Senanayake Mudiyanselage Harshana Mahendra Kumara Senanayake* $\Delta$ (iD \\ Office of the Judicial Medical officer, Teaching Hospital Anuradhapura, Sri Lanka.
}

\begin{abstract}
Introduction
Even though Cardiomyopathy is sometimes discovered during postmortem examinations of sudden deaths, NonCompact Cardiomyopathy is very rarely found during medico-legal practice. Non-Compact cardiomyopathy (NCM) is a myocardial disorder, which is thought to occur due to the failure of left ventricle compaction during embryogenesis resulting two-layered ventricular wall, comprising a thinner compact epicardial layer and an inner non-compacted layer, with prominent trabeculations associated with deep, intertrabecular recesses that communicate with the ventricular cavity but not with the coronary circulation.
\end{abstract}

\section{Case reports}

The author had found only two cases during the 20 years of his carrier. They were 2 years and 3 years old children died on admission when brought to the hospital for treatments for difficulty in breathing. Postmortem examinations of both showed cardiomegaly and severe multiple trabeculations with deep intertrabecular recesses of the ventricular myocardium. Both had died due to heart failure due to Non-Compact Cardiomyopathy. Patients suffering from NonCompact Cardiomyopathy can develop heart failure, arrhythmia or embolic phenomena at any age.

\section{Conclusions}

It is a rare cause of sudden death found in postmortem examinations especially in children.

Keywords- non-compact cardiomyopathy, trabeculation, ventricles

Copyright: @ 2017 with the Medico-legal Journal of Sri Lanka.

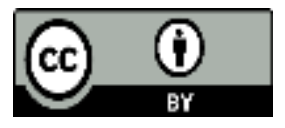

This is an open access article distributed under the terms of the Creative Commons Attribution License, CC BY 4.0 which permits unrestricted use, distribution and reproduction in any medium, provided the original author and source are credited.

Funding: None, Competing interests: None

Received: 14 November 2017

Accepted revised version: 20 March 2018

Published: 01 April 2018

http://orcid.org/0000-0002-0441-5970

*Corresponding author: Senanayake SMHMK, Email address: senanayakekumara@yahoo.com, Tel: +94718195569

Cite this article as: Senanayake SMHMK. Non-Compact Cardiomyopathy: A Rare Pathology in Sri Lankan Context Medico-Legal Journal of Sri Lanka, 2017;5(2):22-25

DOI: http://doi.org/10.4038/mljsl.v5i2.7360 


\section{Introduction}

Cardiomyopathy is a group of inherited disorders of heart which includes hypertrophic cardiomyopathy, dilated cardiomyopathy, arrhythmogenic right ventricular cardiomyopathy, restrictive cardiomyopathy, takotsubo cardiomyopathy, peripartum cardiomyopathy and non- compact cardiomyopathy. ${ }^{[1]}$

Non-Compact Cardiomyopathy (NCM) is a genetically heterogeneous congenital disorder of the myocardium, which is thought to occur due to the failure of ventricle compaction during embryogenesis, leading to distinct morphological characteristics in the ventricular chamber. The characteristic features of NCM have been described as including a two-layered ventricular wall, comprising a thinner compact epicardial layer and an inner non-compacted layer, with prominent trabeculations associated with deep, intertrabecular recesses that communicate with the ventricular cavity but not with the coronary circulation. Commonly, the left ventricle is involved but the right ventricle also can be involved. ${ }^{[2]}$

\section{Case 1}

Three-year-old boy, diagnosed with tricuspid regurgitation, ventricular septal defect and occasional wheezing was found dead on admission when he was brought to the hospital to take treatments for wheezing. Postmortem examination showed marked cyanosis, pericardial effusion, pulmonary oedema, cardiomegaly, small left ventricle cavity and large right ventricle with increased trabeculae. The left ventricular wall thickness was $8 \mathrm{~mm}$ and right ventricular wall was $12 \mathrm{~mm}$. Microscopically left ventricular wall was normal but the right ventricular wall showed prominent ventricular trabeculation and deep recesses, the non-compact inner area of the right ventricle was $1 \mathrm{~cm}$ and compact outer -area was $0.2 \mathrm{~cm}$ (photomicrograph 01). Cause of death was issued as heart failure due to congenital heart diseases including ventricular septal defect, tricuspid incompetence and non-compact cardiomyopathy of the right ventricle.

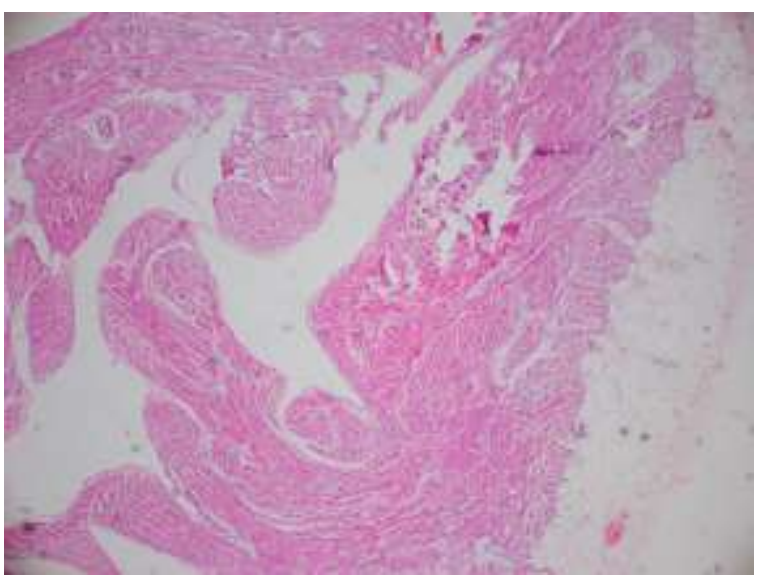

Photomicrograph 01: Right ventricle of case 1 (Haematoxylin and Eosin, 4x10)

Since this condition was first diagnosed at autopsy, first-degree family members were advised to obtain cardiology opinion for family screening.

\section{Case 2}

Two years old girl was found dead on admission to a local hospital. She had been diagnosed with tricuspid regurgitation and non-compact cardiomyopathy with dysfunction of left ventricle because she had been investigated for difficulty in breathing after birth. Postmortem examination showed pericardial effusion, $5 \mathrm{~mm}$ thick right ventricular wall, $7 \mathrm{~mm}$ thick left ventricular wall, multiple trabeculations of both ventricles (Fig. 01) and pulmonary oedema.

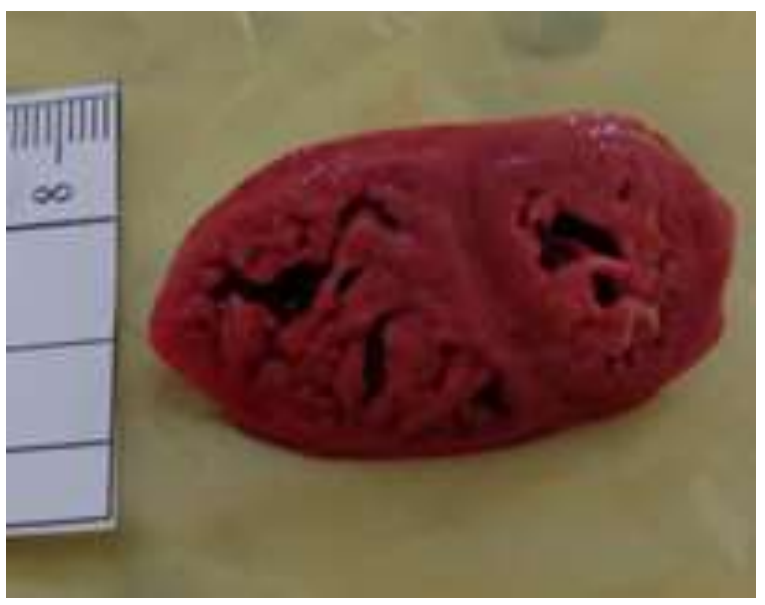

Figure 01. Biventricular involvement of case 2 
Histology revealed prominent ventricular trabeculation and deep recesses, compact outer layers (right ventricle wall thickness was $1.2 \mathrm{~mm}$ and left ventricle was $1.6 \mathrm{~mm}$ ) and non-compact inner layer (right ventricle was $3.8 \mathrm{~mm}$ and left ventricle was $5.4 \mathrm{~mm})$. Cause of death was issued as heart failure due to congenital heart diseases including tricuspid incompetence and Non-Compact Cardiomyopathy of both ventricles.

\section{Discussion}

NCM is a very rare congenital heart disease. The author had found only two cases during 20 years of the carrier involved with $10 \quad 600$ postmortem examinations. NCM may be found during the postmortem examination as a diagnosed or undiagnosed case. The triad of heart failure, ventricular arrhythmias, and systemic embolic events comprise the typical complications in patients and may occur at any age. ${ }^{[3]}$ Therefore, these cases have a higher chance of undergoing inquests and postmortem examinations due to sudden deaths. However, the initial clinical presentation is variable and the patient may be asymptomatic (frequently diagnosed during a family screening) or present as sudden death or any of the clinical features and complications including breathlessness, fatigue, feeling dizzy, syncope, palpitations, and ankle swelling. ${ }^{[4]}$

When this condition is diagnosed at the autopsy, firstdegree family members should be referred for cardiology screening. Even though thickened ventricular walls and prominent trabeculae are easily noticed at autopsy, histopathology is an important investigation.
NCM may be found alone or in combination with an abnormality of heart or any other organ such as ventricular septal defect, atrial septal defect, patent ductus arteriosus, Ebstein's anomaly, patent foramen ovale, dilated cardiomyopathy, mitral regurgitation and pulmonary hypertension. ${ }^{[5]}$

Interstitial fibrosis and endocardial fibroelastosis, anastomosing broad trabeculae, coarse trabeculae resembling multiple papillary muscles and spongelike interlacing smaller muscle bundles were found histologically. The absence of well-formed papillary muscles is considered as the best clue for the diagnosis. Histopathology is very important to prevent over diagnosis of this rare condition because some normal hearts may show prominent papillary muscles resembling NCM. ${ }^{[6,7]}$ Both above cases were associated with other congenital heart diseases, presented with dyspnoea, had died of heart failure. Case 1 showed NCM only in right ventricle and case 2 showed the involvement of both ventricles. Case 1 presented to the inquest as undiagnosed case and Case 2 presented as sudden death in a diagnosed case of NCM. In relation to the Case 2, cardiologist had informed relations about poor prognosis of the condition and performed family screening.

\section{Conclusion}

Non-Compact Cardiomyopathy which is detected with prominent trabeculae of ventricular wall is a very rare congenital heart disease found at the medico-legal practice of Sri Lanka.

\section{References}

1. Carrilho FP, Ameida AG, Pinto FJ. Non-compaction cardiomyopathy: prevalence, prognosis, pathoetiology, genetics and risk of cardioembolism. Curr heart Fail rep. 2014;11(4);393-403 DOI: http://doi.org/10.1007/s11897-014-0227-3.

2. Mitrofanova LB, Moiseeva OM, Khashchevskaya DA, Mitrofanov NA, Pervunina TM, Zaklyazminskaya EV et al. Left Ventricular non-compaction: A clinical and morphological study. Arkh Patol.2016;78(2):29-35 
3. Burke A, Mont E, Kutys R, Virani R. Left noncompaction: a pathological study of 14 cases. Human Pathology.2005;36(4):403-11.

DOI: http://doi.org/10.1016/j.humpath.2005.02.004

4. Yin L. Non-compact Cardiomyopathy of ventricular non-compact syndrome? Journal of Cardiovascular Ultrasound. 2014; 22(4): 165-72

DOI:http://doi.org/10.4250/jcu.2014.22.4.165

5. Sherling KW, Nuttli T, Newmann WP, McGoey RR. Left Ventricular Noncompaction Cardiomyopathy. Journal of LA state medical Society. 2013; 165(3): 150-2

6. Bozic I, Jurisic Z, Bozic D, Carevic V, Batinic T, Fabijanic D. Left ventricular noncompaction. Lijecnicki Vjesnik. 2015;137(9-10):318-25

7. Mariana F, Grigore T, Mihaela G. Left ventricular Non- Compaction- Challenges and Controversies. Maedica (Buchar) 2014;9(3):282-8 